\title{
Año 2000: Los rostros del otro
}

Morder el aire, morder las piedras nuestra carne no es ya de hombres. Morder el aire, morder las piedras nuestro corazón no es ya de hombres.

Franco Fortini.

A medida que se acerca el fin de un milenio más, parece que ha llegado la hora de "limpiar la casa". Los distintos "grupos" ideológicos, que luchan por legitimarse ante tanto escéptico, se apuran a definir sus posturas frente a una realidad que lleva mucha prisa. Los descubrimientos científicos -el caso de la oveja "Dolly" es un ejemplo-, el avance totalmente imparable de las nuevas tecnologías de la información y la comunicación, los desmanes contra la vida humana cometidos por diversos fundamentalismos y nacionalismos, en fin, el avance de esta época que nos ha tocado vivir, evidencian aquella vieja constatación hegeliana de que la reflexión ética profunda y global parece ir siempre a la zaga de los hechos y los esfuerzos de las ciencias. En fin, se trata, como siempre, del viejo ser humano y de eso que vagamente llamamos su historia. No nos extrañe, por lo tanto, que los de aquí y los de allá se las vean a palitos con sus "respuestas".

Pero este esfuerzo de clarificación no siempre parte de la realidad de los hechos o de la diversidad de opiniones. A veces, lo que prima en la construcción de un edificio ideológico —en absoluto algo negativo "a priori"-es la cerrazón a lo que pasa "allá afuera", cuando no la verdadera intención de encubrir la realidad. En esta ocasión vamos a referimos a un caso de esos: el presunto discurso moral que subyace a tantos planteamientos y que adolece de una furiosa intolerancia de las diferencias, el temor a lo otro, a lo extraño, fenómeno que se vierte en diversas esferas de la praxis y del pensamiento. Ahora bien, ¿qué entenderemos específicamente por intolerancia?

La respuesta a esa primera pregunta sólo la podrá articular el lector al final de nuestra exposición, la cual es, por supuesto, parcial y limitada. Esta parciali- 
dad nos ha impedido abordar el problema de la intolerancia en dos momentos: en primer lugar, intentamos un tratamiento filosófico del asunto desde la categoría de alteridad; seguidamente, aplicamos estas reflexiones a los casos concretos de la intolerancia por razones económicas, étnico-culturales y por el tipo de elección de la propia vida privada. Por supuesto que nuestras conclusiones "adolecerán" de la misma parcialidad y limitación de la que hacíamos referencia arriba, pero no dudamos que éstas terminarán deviniendo en resultados positivos. Después de todo... el debate quedará abierto.

La mencionada categoría de alteridad es el nombre filosófico que se le da a la pregunta fundamental por el "otro": ¿quélquién es el otro? Esta interrogante ha recorrido múltiples veredas a través de la historia. Se trata de una pregunta profundamente ligada a esa otra tan fundamental: ¿qué es el hombre? A lo largo de la historia de la filosofía, las respuestas que se han dado en torno a esta última sugieren alguna pista en torno a la primera. En la antigüedad, ser humano implicaba poseer ciertas características "comúnmente aceptadas": racionalidad, lenguaje, inclinación hacia la vida ciudadana (el zoon politikón aristotélico)... Por lo tanto, el otro es aquel que se separa de tales propiedades. A los habitantes del siglo XX no nos sería escandaloso aceptar este presupuesto, por lo demás bastante obvio, en el caso de los animales, pero basta una somera revisión histórica para darnos cuenta que hasta hace menos de cien años entraban en el rango de no humanos los extranjeros, los esclavos negros, los indígenas y las mujeres, todos ellos bajo sospecha de irracionalidad, o sea, bestialidad. El caso es que, desde los albores de la civilización, la línea divisoria que establece el límite de lo humano y lo no humano ha proporcionado también argumentos para hablar de la alteridad.

Pero no siempre esta alteridad ha sido enunciada de modo tan radical. Podemos pensar en una alteridad que no necesita de la frontera hombre-bestia, pero para eso será necesario situarnos en la modernidad, en el debate gnoseológico y antropológico que inauguran hombres como Descartes, Leibniz y Kant. La reflexión moderna sobre el sujeto necesitará dar cuenta del fenómeno de la alteridad. Pero, fieles a sus bases categoriales, esta se reducirá a una mera proyección de la conciencia del mismo: el yo pone al otro, siempre dentro del ámbito totalitario de la conciencia. Este solipsismo antropológico llevará a convertir al otro en mero producto del yo, con lo cual se proporciona un gran apoyo antropológico a toda la lógica del mercado y del capitalismo naciente. En efecto, para las nuevas relaciones sociales burguesas, la objetivación del otro no es una mera pirueta teórica, sino una idea con una enorme utilidad mercantil y, posteriormente, industrial. Todavía ahora podemos sentir la fuerza de tales ideas en nuestra moderna sociedad de consumo, en la cual el otro no sólo se reduce a mero "factor de producción", medio en función de un fin determinado, mero objeto de placer o, en el peor de los casos, obstáculo ante el cual mi "libertad" - léase la libertad del capitalista- se constriñe y exige su pronta eliminación. Por su parte, los 
esfuerzos socialistas para la construcción de una antropología diferente estarán durante mucho tiempo lastrados por el afán de totalidad modemo, acorde a las pretensiones de progreso y eficiencia tan caros a la ilustración (iy nunca restringidos al ámbito capitalista!).'

Es hasta el siglo XX que podemos asistir a un discurso, a todas luces novedoso, en torno a la problemática del otro hombre. La fenomenología de Edmund Husserl dará luz verde a nuevas formas de abordar teóricamente la alteridad y poco a poco el solipsismo será despojado de toda credibilidad. Pero esto no significa que se han terminado los inconvenientes, ya que, si bien es cierto se supera la soledad angustiosa en un Husserl que necesita del otro para llegar al mundo o en un Martin Heidegger que invoca al destino, la etnia o el suelo común en aras de un proyecto común ${ }^{2}$, estos planteamientos no pueden salir de un marco egotista, ya sea porque el punto de partida sigue siendo el yo (Husserl) o en tanto la diferencia es sacrificada en aras de lo común (Heidegger). Las contradicciones de una filosofía que pretende superar el solipsismo, pero sin salirse de la fenomenología, serán puestas en el tapete por Jean-Paul Sartre, el cual recuperará la angustia bajo la forma de náusea, de la cual el ser humano tiene experiencia justo por el encuentro con su mismidad, la cual es libertad. El humano es viviente concreto y libre, que se encuentra en el mundo junto a otros como él. Pero estos otros no están allí más que para recordarle su labilidad, sus limitaciones, para $a$-vasallarlo con su mirada ${ }^{3}$. Desde esta perspectiva, si bien es cierto estamos ya en el terreno del hombre concreto, la visión marcadamente fatalista de la alteridad en la filosofía de Sartre no logra deshacerse de su tan penosa carga: el yo, la conciencia egoísta que sigue dando la pauta en cuanto a la configuración del otro.

Un giro revolucionario de esta visión de la alteridad llegará con Martin Buber, en el cual encontramos la inversión del proceso de análisis que había primado hasta ahora: no es el yo el punto de partida sino el tú. La palabra fundamental yo-tú que encontramos a la base de todo el lenguaje es la muestra de que la relación cognoscitiva - signada por otra palabra fundamental, pero subordinada a la anterior: yo-ello - no es la relación humana principal; antes bien, el encuentro con el otro no sólo es anterior sino que es la base de cualquier otro tipo de relación, a la vez que fin último de la misma vida humana ${ }^{4}$.

Más radical aún será el planteamiento de Emmanuel Lévinas. Este filósofo retomará el análisis de raíces judias presente en Buber, pero lo llevará al extremo de proponer un nuevo esquema totalmente nuevo: no sólo hay que salirse del absolutismo del yo, sino que ni siquiera es posible referirse al otro como un tú, so pena de que quede en simetría con el yo. Al contrario, el otro se me presenta como inalcanzable e infinito. Por lo tanto, es preciso reconocer que al otro no lo puedo aprehender de ninguna manera, dada su asimetría con respecto de mí: siempre el otro será para mí el incognoscible absoluto. A lo sumo, puedo hablar 
con él, pero no hablar de él, ya que, entonces, lo reduzco a mis categorías y objetivaciones, lo convierto en cosa. Pero el asunto no termina alli, ya que me hago responsable de este innombrable. El otro exige de mí no sólo que renuncie a querer someterlo con mis categorías (Buber), sino que me haga cargo de su destino. Esto lleva a Lévinas a plantear que la filosofia primera es la ética ${ }^{5}$.

No obstante, parece que el radicalismo levinasiano puede, en cierto modo, colocar al otro en una esfera de inaccesibilidad tal que no nos deja más opción que el fatalismo de la innegable condición lábil del humano, cuyos esfuerzos dirigidos a la satisfacción de una vida intersubjetiva en responsabilidad absoluta del otro se ven inevitablemente frustrados por la absoluta desproporción entre su aspiración infinita y sus posibilidades finitas. Por lo demás, este carácter del otro se halla sobre la base de la realidad del Otro absoluto, el Dios innombrable común a la tradición judía. Algunos analistas del pensamiento de Lévinas han notado este problema específico de la absoluta trascendencia del otro, lo cual limita no sólo en el campo de la teología —un Dios tolalmente otro no se caracteriza precisamente por su cercanía al hombre necesitado de él一, sino también en el de la ética —unos presupuestos metafísicos que convierten la libertad humana, condición esencial para la élica, en poco menos que un fantasma, por no hablar de la responsabilidad, la cual es reducida a perenne frustración ${ }^{h}$.

Por nuestra parte, nos parece que la crítica a Lévinas puede hacerse en un nivel más fundamental: no es para nada evidente la exigencia ética que me presenta el rostro del otro. El intento de Lévinas de hacer equivalentes el encuentro empírico con el otro y la responsabilidad a la que estoy exigido falla en la mera constatación empírica de lo inverso: el rostro del otro puede ser interpretado como exigencia de violencia hacia él... o mera indiferencia. El problema estriba justamente en que la exigencia, sea esta de responsabilidad o absoluta indiferencia ante el sufrimiento del otro, es una interpretación y, por lo tanto, no pertenece al ámbito de la aprehensión primordial de realidad, la mera evidencia empírica que se convierte en terreno común para la discusión, "lugar" desde donde, a nuestro juicio, habría que fundamentar la antropología filosófica y la ética ${ }^{7}$. Si esto no es así, corremos el riesgo de convertir esa exigencia de responsabilidad absoluta y primordial en una nueva metafísica absolutista, interpretación apriorística que anula la libertad y nos hace caer de nuevo en la tan odiada totalidad.

No obstante lo anterior, Lévinas acierta en el giro antropológico que le imprime a sus reflexiones, ya que su concepción de la alteridad toma muy en cuenta la necesidad de salirse radicalmente del imperialismo del yo. En este sentido, son bastante sugerentes sus ideas. Además, este filósofo ha planteado a la filosofía occidental un reto ineludible, ya que esta se ve obligada a repensar sus propias raíces y fundamentos desde su "atrevida" afirmación de que no es la ontología sino la ética la filosofía fundamental. 
Efectivamente, el otro como irreductible a las conceptualizaciones del yo y la ética como filosofía primera son dos ideas que retomará con mucha energía el argentino Enrique Dussel. En su obra filosófica más reciente ${ }^{\sharp}$, Dussel trabaja estas ideas dentro del contexto de su propia propuesta: la ética de la liberación. Esta no se elabora dialogando únicamente con Lévinas ( ¡ni siquiera se trata del interlocutor principal!), sino con la casi totalidad de las tradiciones morales culturales e históricas —eticidades-, así como con las diversas escuelas filosóficas y sus respectivas "éticas". No obstante, podemos sostener que el principal interlocutor de Dussel es el filósofo alemán K. O. Apel y su teoría ética que se sostiene en lo que Dussel llama principio de validez intersubjetiva. En grandes líneas, este principio se refiere a que en la búsqueda de un criterio ético de validez universal, basta y sobra con el diálogo simétrico entre los interesados $\longrightarrow$ sus representantes-, sobre la base de un modelo ideal, la comunidad de comunicación, en el cual se puede ejercer ese diálogo en igualdad de condiciones. Frente a este planteamiento, Dussel llama la atención no sobre su falsedad sino sobre su insuficiencia: si bien es cierto que el criterio ético se adquiere en el diálogo, tal diálogo no se hace sobre una base abstracta sino presuponiendo un principio anterior, el principio material de la ética, el cual podría formularse como un imperativo práctico que consiste en que toda decisión con pretensión de bondad deberá contribuir al sostenimiento y reproducción de la vida humana en todas sus dimensiones básicas (biológica, individual, interpersonal-comunitaria, etc.). Esta responsabilidad primordial de la que habla Dussel no hace más referencia que a la mera constatación empírica del funcionamiento de nuestros razonamientos, los cuales no se hacen únicamente sobre la base de una lógica meramente formal, sino también sobre una exigencia de "no contradicción" práctica. Por ejemplo, un juicio de hecho como "Estoy sediento" caería en una contradicción práctica si se le separara de este otro: "Debo beber agua". En conclusión, si bien es cierto que no podemos aceptar que la naturaleza, sea tomada en un sentido biológico o metafísico, nos exija un determinado comportamiento a priori, anterior a cualquier reflexión libre, también es cierto que toda toma de decisión libre se hace sobre la base de ese esquema racional que, si es coherente con sus mismas estructuras lógicas, no puede incurrir en contradicciones que pongan "entre paréntesis" su básica condición de posibilidad: la vida humana concreta, que es anterior a la condición de sujeto racional.

Esto que acabamos de plantear nos aclara en qué sentido la ética es el fundamento de la filosofía en Dussel. Éste lo expresará mejor con la frase "la razón es la astucia de la vida", con lo cual la primariedad de la ética con respecto a cualquier otra reflexión filosófica queda bastante clara. Pero, se nos preguntará, ¿qué con la reflexión sobre el otro? Aquí es donde aparece el tercer principio de la ética de Dussel - ya hemos mencionado dos-y las consecuencias de éste en lo que es propiamente su ética de la liberación. Veamos. 
A primera vista, lo que Dussel plantea podría adolecer de cierto totalitarismo, en el sentido de que la exigencia ética del respeto de la vida en todas sus dimensiones básicas requeriría de un superhombre o un estado omnipotente, "panóptico y todopoderoso", capaz de forzar la realidad social, caótica y dinámica, hacia una "utopía" socialista que se encargaría de limar las diferencias y eliminar la individualidad y la libertad. Sin embargo, nuestro autor no es tan ingenuo como para no ver lo que sólo un ciego no vería; basta con el fracaso de los proyectos socialistas por todos conocidos, para volver pueriles las pretensiones de semejante "dictadura de los buenos"'. Es por estas realidades tan evidentes que Dussel, repito, no cae en la seducción del proyecto totalizante socialista. Su esquema de la ética fundamental incluye una constatación importante: la reflexión ética no es más que pretensión de bondad, que en ningún modo garantiza que en todas las circunstancias posibles se logrará llevar a buen término los ideales morales. Es por eso que propone el principio de factibilidad, en tanto el diálogo ético que se desarrolla sobre la base de la necesidad de reproducir la vida no puede eludir las condiciones concretas y las posibilidades reales (naturales, individuales, sociales, históricas, etc.) que permitan poner en práctica sus sugerencias. Desde esta perspectiva, las pretensiones de cualquier proyecto totalizante, por muy buenas que sean sus intenciones, estarán destinadas in toto a fracasar, pues en su base se escondería un afán de omnipotencia, propio de la racionalidad ilustrada, que ignora la complejidad de la vida humana y las limitaciones de los afanes humanos. Otro problema será el de los modelos socioeconómicos o políticos que deberán concretizar las propuestas éticas, los cuales serán tan falibles como necesarios, pero se trata de un asunto en el que Dussel no interviene, por lo menos en esta ocasión.

Vemos entonces que Dussel se mueve en un horizonte antropológico y ético postmoderno, dado el carácter abierto que tiene su modelo ético. Tanto es esto así, ¡que el modelo no sólo puede fallar sino que es del todo probable que fallará! Esto explica que sea en la segunda parte de su libro (hasta ahora nos hemos referido sólo a la primera parte) donde desarrolla propiamente su ética de la liberación. Esta consiste, simplificando mucho, en la interpelación que ejercen las víctimas del sistema social injusto contra dicho sistema. El otro se nos presenta aquí fundamentalmente como víctima, pero no sólo del sistema en cuya raíz se halla la más pura iniquidad, sino, y sobre todo, del sistema que pretende ser justo, bueno y correcto. En efecto, no es el caos sino el orden quien somete a grandes proporciones de la humanidad a una condición de desamparo, que llega incluso hasta la muerte. Por lo tanto, podemos pensar, dada la condición falible de la praxis humana -por las razones apuntadas arriba-, que siempre encontraremos víctimas, lo cual no es una invitación a la inmovilidad ética, como cuando algunos interpretan aquel pasaje del evangelio: "Pobres siempre tendréis con vosotros; pero a mí no siempre me tendréis" (Jn 12, 8). Al contrario, de lo que se trata es de reconocer a la víctima que está allí afuera, tras el 
sistema y al otro lado de lo que habitualmente se considera solidaridad. Justo aquí podemos percibir la expresión primaria y fundamental de la intolerancia: la ausencia de solidaridad con el que sufre. El otro sufriente, la víctima, se presenta como intolerable a partir de las categorías que priman en nuestra sociedad, porque la alteridad consiste en que el otro es tal porque está justo al otro lado de las propias categorias éticas y antropológicas, las cuales están fundadas en el sistema social vigente, el único que se reconoce y acepta. El egoísmo que permite esas muertes no es el de quien carece de principios éticos, sino de quien se sostiene sobre principios que suponen unos excluidos, excluidos porque son de otro modo que él. Hay que recalcarlo: la in-solidaridad es una forma de in-tolerancia.

Por supuesto que tendríamos que aceptar que no todo agente individual o social actuará necesariamente movido por una preocupación ética sincera: nos referimos al cínico, el cual no entraría propiamente en nuestro esquema, dado el carácter meramente estratégico de su intervención en la discusión moral"'. De igual modo tendríamos que reconocer que no siempre el ser humano actúa luego de una detenida reflexión; es más, a veces lo hará en contra de lo que podrían ser sus principios previamente aceptados... y muy a su pesar". En cuanto al primer caso, la interpelación al cínico tenderá a desplazarlo hacia la esfera de la irracionalidad, con lo cual sencillamente nos colocamos más allá de la discusión ética, por ejemplo, no se podría universalizar la pretensión cínica de que la muerte es una opción éticamente válida - como cuando se habla de los que mueren de hambre como "distorsiones inevitables del mercado"-, sin convertirla en una exigencia de validación universal del suicidio, lo cual nos llevaría a una contradicción práctica, en tanto el que formula la proposición lo hace sobre la base de una estructura racional que presupone el esquema de reproducción de la vida, según lo expusimos arriba'2. En cuanto al asunto de la diferencia entre decisión moral "reflexiva" e "irreflexiva", obviamente que nos ponemos fuera del esquema de Dussel, pero no lo invalida, ya que se asume desde la mención del carácter falible en el ser humano, el cual incluye tantas situaciones de irracionalidad, desde lo difícil que es hablar de reflexión ética en un adulto con retardo mental, hasta los casos más graves de personalidad antisocial, pasando por el problema, tal vez más común, que apuntábamos arriba.

Pero, volviendo a nuestro problema del otro, en Dussel podemos referirnos a éste con mayor concreción, pues ya se nos muestra con más claridad: con un rostro. Este rostro es plural, no unívoco, ya que someter al otro a una epifanía uniforme sería volver a encasillarlo en una categoría reductiva. El otro es el niño de la calle, el trabajador indocumentado, el homosexual que sufre la discriminación de sus propios conciudadanos... Pero esta pluralidad no se diluye en el caos y en el relativismo de una alteridad "abstracta", ya que eso sería, en el fondo, otro tipo de "disolución" de las peculiaridades. Hay un fondo común a los diversos rostros de la alteridad: el sufrimiento que expresa el otro humano, su condición de insatisfacción de una necesidad, que es tal insatisfacción porque él cla- 
ma por ella. La mera constatación empírica que tenemos los humanos de lo que es el sufrimiento nos lleva a considerar como preferibles aquellas acciones que lo evitan; y, como bien lo plantea Umberto Eco, bien pronto nos damos cuenta que pasa lo mismo con los demás seres humanos ${ }^{13}$. ¿Quiere decir esto que en todos los humanos se tiene una experiencia idéntica del dolor? No necesariamente, pero sí hay unos límites que son comunes en buena medida: este límite lo expresa muy bien la famosa máxima: "No hagas a otros lo que no quieras que te hagan a tí". El constreñimiento de los propios anhelos, la privación de lo que nos resulta indispensable para la vida, no sólo para la sobrevivencia sino para la vida buena, eso es lo que consideramos como malo.

Hasta aquí se nos objetará que no todos los seres humanos clamamos por lo mismo. En efecto, habrá quien considere de mucha importancia la vida intelectual frente a quien no daría un comino por ella o, también, quien tenga en alta estima la satisfacción de sus deseos sexuales, lo cual tiene sin cuidado a un asceta. ¿Es que habría que uniformar el contenido de nuestras apetencias? ¡Nada más lejos de nosotros! Más bien, podemos encontrar una uniformidad, no en el contenido de los deseos, sino en que existe un deseo; no en el objeto de la apetencia sino en la apetencia misma. Y es aquí donde muchos pensadores han encontrado la fuente de las justificaciones morales del comportamiento de las personas: en el deseo de satifacer las propias necesidades ${ }^{14}$. Claro está que la satisfacción de las necesidades de todos encontrarán dificultades reales, como, por ejemplo, en el hecho de que deseos legítimos de unos chocan con los deseos legítimos de otros. Se dirá: "Habrá que ponerse de acuerdo". Pues bien, ijusto en eso consiste el diálogo ético!

Por otro lado, hacemos notar que hasta ahora partimos del supuesto de que hay ciertas necesidades que se nos presentan a todos como básicas y justificables: necesidades legítimas. Parecería absurdo pensar que hay seres humanos que pueden argumentar en contra del derecho de otros humanos a tales necesidades universalmente aceptadas. Lastimosamente, tales sospechas están bien fundadas. Un filósofo que aborda este modo particular de intolerancia es el utilitarista Peter Singer, quien de un modo muy claro expone la razón por la cual los "ricos" - aquellos que tienen satisfechas sus necesidades humanas básicasdeben proporcionar un auxilio concreto y real a los "pobres" - léase, los que carecen de tales necesidades básicas. Su razonamiento es más o menos así: "La vida moral consiste en hacer lo que consideramos deseable, no sólo para mí sino para las otras personas. Dado que la satisfacción de las necesidades humanas básicas es el mínimo aceptable para todo ser humano y que estamos dispuestos a contribuir a la adquisición de las mismas por parte de todos, entonces, es absolutamente injustificable el no proporcionarlas a quien lo solicita". Y esto, entiéndase bien, admitiendo que pueden existir verdaderos conflictos entre las necesidades de unos y de otros. En cualquier caso, siempre habrá que privilegiar las necesidades básicas de los demás por encima de las nuestras no tan urgentes ${ }^{15}$. 
No es ocioso agregar que dentro del rango de tal responsabilidad no entran sólo nuestros conciudadanos, sino también los pobres de cualquier nacionalidad, los refugiados y los trabajadores migrantes, incluidos los extranjeros indocumentados, los cuales, en la mayoría de los casos, han tenido que anteponer su vida a los formalismos y requisitos legales que, en cualquier caso, son siempre secundarios ${ }^{16}$.

Por otra parte, vale aclarar que el razonamiento de Singer no parte de una noción particular de los derechos ni de una idea universal a priori a la experiencia humana concreta. Se trata únicamente de la mera constatación del otro como carne sufriente: es el ejercicio de la solidaridad ante el dolor del otro, frente a los problemas que encuentra para desarrollar plenamente su vida. Ante la ya muy conocida pregunta: "¿Soy yo acaso el guardián de mi hermano?" (Gn 4,9), tenemos que contestar que sí, lo cual no significa necesariamente que se trate de un razonamiento del tipo "lo que le sucede a él es culpa mía", razonamiento que en todo caso nos pone ante una perspectiva negativa e inútil de la responsabilidad; más bien, estamos ante la exigencia ética de hacernos responsables, "de aqui en adelante", por que el otro no sufra más.

Más dificultades podríamos encontrar en el problema de las necesidades en torno a las cuales no hay suficiente consenso sobre su legitimidad. $Y$ es justo aquí que vemos la importancia de nuestra caracterización del otro, ya que, así como el otro tiene muchos rostros, la intolerancia también tiene muchas máscaras. Hemos visto que la solidaridad no presupone una segura o vaga mismidad, una pertenencia a valores, principios, ideas o costumbres comunes, sino que, más bien, tal solidaridad se funda en la sensibilidad radical y racional ante el rostro concreto del otro, ante su rostro, y no cualquier máscara que mi egoísmo le asigne. Es asi que la solidaridad presupone la tolerancia de las diferencias y la aceptación del otro entero e integro. Indudablemente que esta actitud de apertura y receptividad ante lo propio del otro no se agota en la visión "superficial" de su rostro: es preciso que el otro hable, que se exprese desde lo más profundo de su corazón. La tolerancia debe impregnar lo más profundo de su intimidad, sus profundos deseos y su anhelo de autenticidad.

Umberto Eco nos proporciona algunas pistas de reflexión al respecto, en tanto aborda el problema, mencionado arriba, de las migraciones ${ }^{17}$. Efectivamente, la intolerancia se expresa en toda su crudeza contra aquel que no sólo me pide ayuda sino que, además, me resulıa extraño. Pero lo que se presenta como un fenómeno ineludible, las migraciones y sus consecuencias ( $v$. gr. mestizaje, intercambio cultural, etc.), así como el rechazo de éstas, no son más que un escenario y caracterización más de algunos fenómenos de intolerancia que no exigen una frontera estatal, nacional o cultural. También dentro de los límites de un país puede arlicularse la pregunta: "¿Cuándo te vimos forastero y te acogimos?" (Mt 25,38). Si adjudicamos al término forastero toda su fuerza y signifi- 
cación, tendremos que reconocer bajo el mismo no sólo al extranjero sino, además, al "marero", al drogadicto, al homosexual, al enfermo de SIDA...

El terreno que pisamos ahora no es más el de la necesidad ética de llegar a un acuerdo sobre nuestros criterios de acción, como lo hemos planteado arriba, sino que estamos ante la ética en tanto exigencia de justificación racional de nuestras preferencias. Es indudable que no sólo hay que pensar la ética en términos de acuerdo entre sujetos, ya que no todas las actividades humanas exigen semejante cosa. Podemos poner un sinnúmero de ejemplos de situaciones en las que el acuerdo es sencillamente irrelevante: el consumo de bebidas alcohólicas o drogas, la afición por la "ruleta", las preferencias sexuales son sólo algunos de los casos en que no hace falta un acuerdo social o interpersonal. Pero, ¿y los daños en las familias debido a las drogas o al alcohol? ¿Qué con las economías destrozadas por el "juego"? ¿Y los daños a la sociedad que generan los homosexuales? Pues, si se ve bien, nos daremos cuenta que ninguno de estos "males" se debe al valor en sí del acto en cuestión, sino a una serie de circunstancias que, en rigor, les son ajenas. No es el consumo de alcohol lo que destruye una familia sino su abuso. Dado que el alcohol es una droga que mata tanto como cualquiera, podemos aplicar el mismo razonamiento a los enervantes y alucinógenos, ya que sostener, como hacen algunos, que un gramo de heroína es equivalente a una botella de vodka en términos de acción adictiva o destructiva sólo convierte el asunto en una problema de cantidades y de tiempo que no afecta en nada el asunto ético propiamente. El mismo razonamiento podemos aplicar al caso del "jugador empedernido", ya que, si hay un mal, este lo encontramos de nuevo en la incapacidad para determinar sus propios límites. ¡Pero esto puede ser igual de "mortal" si se trata de abuso en la comida, el trabajo o el celo religioso!

El caso de la presunta "inmoralidad" de la homosexualidad —o bisexualidades aún más falaz. Dado que se trata de libre elección de conductas entre sujetos autónomos, y ya que tal actividad compete por su misma indole a ellos solos (el acto sexual sigue siendo, a pesar de las afirmaciones quejumbrosas de más de algún puritano iracundo y voyeurista, un acto privado) ipuede acaso proscribirse o siquiera condenarse tal ejercicio de la libertad fundamental? Pues, si se ve bien, difícilmente se puede sostener en una mano la bandera de la libertad y autonomía individuales $y$, en la otra, la de las prohibiciones que no competen a lo social. Y habrá que dejar claro, además, que las identificaciones de la homosexualidad con la promiscuidad o el acoso sexual no son, de ninguna manera, un argumento a favor de la condena de la primera. ¡Como si no encontráramos suficientes casos de los mismos en el "mundo" heterosexual!

El respeto al otro es justo lo opuesto a ese tipo de intolerancia que se ensaña con lo que no obedece a los criterios de preferencia de un grupo, cultura o sociedad. Junto a la solidaridad, el respeto constituye un valor fundamental que 
no debemos ignorar si queremos vivir en una auténtica sociedad abierta. En esta perspectiva, es interesante constatar que, hace poco más de 250 años, apareció en Europa un libro, probablemente único en su género y en su época, que propuso una perspectiva de los pueblos extranjeros - léase extraños- que sencillamente desafiaba los cánones sobre el tema. Nos referimos al libro de Ludvig Holberg (1684-1754), Nikolai Klimii iter subterraneus, (Copenhague y Leipzig, 1741), en el que se nos narran las peripecias de Niels Klim, quien, al penetrar en un misterioso mundo "subterráneo" - underground-, se encuentra con que, ¡vaya sorpresa!, en ese mundo todos los hombres diferentes conviven en armonía entre sí, sin que se considerara que una manera determinada de vivir fuera la "canónica". En un solo mundo podía encontrarse diferentes usos y costumbres, gustos gastronómicos y preferencias sexuales, rasgos físicos y vestimentas de variados colores, todos ellos coexistiendo en profunda armonía. Nuestra fuente sobre este libro de Holberg resume, en unas cuantas líneas, este mensaje de tolerancia, el cual hemos elegido como colofón de nuestras reflexiones:

"No existe ningún modelo absoluto, ninguna vía obligada. Cuando reina el relativismo, la más esencial de las virtudes humanas debe ser la tolerancia"lı.

\section{Notas}

1. Cfr. Beorlegui, C., "La interpersonalidad y la dimensión social del ser humano", artículo inédito.PRIVADO

2. Cfr. en Lain Entralgo, P., Teoria y realidad del otro, vol.1, Madrid, Editorial Revista de Occidente, 1961, los capítulos correspondicntes a Husscrl (pp. 189-207) y Hcidegger (pp. 299-316).

3. Cfr. Ibid., el capitulo dedicado a Sartrc (pp. 347-377).

4. Cfr. Ibid. , cl capítulo dedicado a Bubcr (pp. 257-280).

5. Cfr. Lévinas, E., "Diálogo y trascendencia", cn Bcorlcgui, C., Lecturas de antropologia filosófica, Bilbao, Editorial Anthropos, 1995, pp. 238-243.

6. Cfr. Bcorlegui, C., "El pensamiento ético-antropológico de E. Lévinas. Su fccundidad y sus insuficiencias", Letras de Deusto 28 (1998) n. 78, 143-172.

7. Cfr. en Ellacuría, I. y Zubiri, X., "Seminario Zubiri de 1978", primera scsión (6/4/ 78), inédito de próxima publicación en $E C A$, la refutación de Xavier Zubiri de la idea ellacuriana de que cl amor es "cvidente" y "aprehendido primordialmente".

8. Cfr. Dussel, E., Ética de la liberación, en la edad de la globalización y de la exclusión, Madrid, Editorial Trotta, 1998. Hay que aclarar que csic no cs cl primer momento en el que Dusscl aborda cl problema de la alteridad desde la ćtica, pero sí cl más "maduro".

9. Tampoco scrvirían mucho a la causa los cjemplos chino y cubano, paises en donde sc danza cntre la demagogia más descarada (paraísos de los pobres donde nadic habla con libcrtad) y la hipocresia a flor de picl (empresas capitalistas, con dólares estadounidenscs, revitalizando sus cconomias).

10. Cfr. Hinkelammert, F., El grito del sujeto. Del teatro-mundo del evangelio de .Juan al perro-mundo de la globalización, San Josć, Edilorial DEI, 1998, pp. 177-237, cn donde se expone una aguda reflexión en torno a csta idea. 
11. Cfr. Singer, P., Ética práctica, Cambridgc University Press, 1995. El autor rctoma tal asunto una y otra vez a lo largo de su discurso.

12. Otro asunto es si el sujcto humano pucde justificar su suicidio. De lo que se trata aquí es de que el suicidio no puede ser critcrio universalizable sin caer en un contrasentido.

13. Cfr. Eco, U., "Cuando entra en escena cl otro", en Cinco escritos morales, Barcclona, Editorial Lumen, 1998, pp. 99-113.

14. Cfr. Singer, P., op. cit.

15. Cfr. ibid., pp. 271-307.

16. Cfr. ibid., pp. 308-328.

17. Cfr. Eco, U., "Las migracioncs, la tolcrancia y lo intolcrable", op. cit., pp. 115-140.

18. Boia, L., Entre el ángel y la bestia, Barcclona, Editorial Andrćs Bcllo, 1997, p. 153. 